\title{
Editorial
}

\section{COVID-19 y Embarazo.}

El brote de neumonía atípica causada por el nuevo coronavirus denominado COVID-19 fue detectada por primera vez en China, a fines del año pasado; y en estos meses se ha ampliado su distribución a más de 70 localidades alrededor del mundo. El virus causante ha sido denominado SEVERE ACUTE RESPIRATORY SYNDROME-CORONAVIRUS-2 O su abreviación SARS-CoV-2. Y la enfermedad causada, CORONAVIRUS DISEASE 2019, "COVID19".

Fue declarada recientemente como una emergencia global de salud pública por la Organización Mundial de la Salud $(1 ; 2)$.

Históricamente las embarazadas han sido afectadas en forma más severa frente a brotes de infecciones respiratorias en comparación a mujeres de grupos etarios similares no-embarazadas. Así se ha descrito en la epidemia de influenza de 1918, la epidemia asiática de influenza 1957-1958, y más recientemente, en la pandemia de $\mathrm{H} 1 \mathrm{~N} 1$ del 2009 y de SARS en 2003 (Cabe recordar que SARS-CoV también es un coronavirus, y comparte $85 \%$ de la secuencia genómica con SARS-CoV-2.). En todas estas epidemias, las embarazadas mostraron tasa de letalidad elevada, mayor riesgo de ingreso a unidades de cuidados intensivos, mayor riesgo de ventilación mecánica y de otras complicaciones infecciosas (3-6, 13).

Coronavirus es una gran familia de virus, frecuentes en población humana y en diferentes especies de animales, incluyendo camellos, gatos y murciélagos. Infrecuentemente, los coronavirus de los animales pueden infectar a la gente $\mathrm{y}$, posteriormente, transmitirse de persona a persona, como ha ocurrido con MERS-CoV, SARS-CoV y, ahora, con COVID-19. Este nuevo virus es un betacoronavirus, como el MERS y SARS-CoV. Los tres tienen su origen en los murciélagos. Se sabe que MERS-CoV y SARS-CoV son capaces de producir enfermedad severa en humanos. El espectro clínico completo, y severidad, secuelas, etc del COVID-19 aún está "en descripción". Los episodios actualmente descritos varían de cuadros leves a severos, incluida letalidad por el mismo. Probablemente, de acuerdo a lo reportado hasta la fecha, la mayoría son cuadros leves, pero enfermedad severa está descrita que se presenta en un 16\%, de acuerdo a reporte de población en China. Los más severamente afectados han sido personas de edad avanzada o con enfermedad crónica concurrente (principalmente pulmonar, cardíaca o diabetes).

De acuerdo a lo reportado (7), el riesgo de letalidad según grupo etario es:

80 años y más: $14,8 \%$

70 - 79 años: $8 \%$

60 - 69 años: $3,6 \%$

50 - 59 años: $1,3 \%$

40 - 49 años: $0,4 \%$

30 - 39 años: $0,2 \%$

20 - 29 años: $0,2 \%$

10 - 19 años: $0,2 \%$

0-9 años: $\quad$ no hay reporte de mortalidad

No existe en la actualidad una vacuna contra este virus, ni medicamentos específicos aprobados para su uso.

\section{EMBARAZO}

Hasta el momento, la información específica en relación al impacto del COVID-19 sobre la embarazada y resultados perinatales es escasa.

La "primera serie reportada" en la literatura es de febrero 2020, que incluye a 9 embarazadas (8).

Basado en ese artículo, hay varios elementos clínicos que podemos rescatar para tener en mente, frente a un cuadro clínico sospechoso. Y, además, varias interrogantes que no logran ser respondidas por esa serie, dado el pequeño número de casos. 
Se trata de una serie retrospectiva de 9 pacientes atendidos en un hospital universitario de China, en un período de 11 días, en enero de este año. Todos los casos corresponden a neumonía en embarazadas de tercer trimestre. Todos confirmados para COVID-19, y todos con estudio de líquido amniótico, sangre de cordón umbilical e hisopado faríngeo al recién nacido al momento del parto (hubo $100 \%$ de cesárea). Y estudio de la leche materna al momento de la primera mamada.

\section{Perfil clínico a tener en consideración:}

Edad: 26 a 40 años (es decir, no discrimina edad en las embarazadas). Ninguna tenía enfermedad crónica asociada. Una tenía preeclampsia. Síntomas más frecuentemente reportados: Fiebre y tos. La fiebre en ninguna superó los $38,8^{\circ} \mathrm{C}$.

Mialgias (3/7). Calofríos no fue un síntoma frecuente.

Existe laco-infección con VIRUS DE INFLUENZA (uno de los casos de esta serie)

Laboratorio: LINFOPENIA (5/9)

Recuento de leucocitos en rangos normales (7/9)

PCR elevada (6/9)

Elevación de enzimas hepáticas (3/9)

Imágenes: TAC tórax con múltiples infiltrados bilaterales "en vidrio esmerilado" (8/9)

Transmisión perinatal: todas las muestras estudiadas (líquido amniótico, sangre de cordón, hisopado faríngeo y leche materna) fueron negativas para COVID-19. No se logró, entonces, demostrar transmisión perinatal del virus en esta serie.

NOTA (en relación a transmisión perinatal): Existe un caso reportado en China, de un recién nacido cuyo parto (cesárea) fue el 06 de febrero 2020. La madre tenía neumonía por COVID-19. El estudio de hisopado faríngeo del niño resultó positivo para el mismo virus, lo que abre la interrogante en relación al riesgo de transmisión in-útero de la infección (9). Sin embargo, existen elementos que no permiten sacar conclusiones al respecto. Primero, la muestra al recién nacido fue tomada a las 30 horas de vida (por lo tanto, no permite descartar que la madre lo hubiese transmitido post-parto). Segundo, no se contó con muestras en líquido amniótico, sangre de cordón o estudio de placenta que apoyará la hipótesis de que la transmisión ocurrió antes del parto.

Entonces, deberemos estar muy atentos a la información futura, pero por ahora no podemos concluir que exista transmisión intrauterina del virus.

Como se mencionó más arriba, SARS-CoV también es un coronavirus, y comparte $85 \%$ de la secuencia genómica con SARS-CoV-2. Y No hubo casos reportados de transmisión materno-fetal en el brote de SARS.

Preguntas no resueltas aún con la escasa información disponible:

No se sabe si existe riesgo de transmisión viral en primer o segundo trimestre.

Si lo hubiese, no se conoce el impacto embrionario/fetal.

En el brote de Influenza A-H1N1 las embarazadas infectadas tuvieron más riesgo de mortinato y de parto prematuro. Hasta el momento se ha reportado parto de pretérmino en algunas embarazadas positivas para COVID-19. Sin embargo, dado los escasos datos no se ha podido atribuir causalidad a la infección materna.

No se ha publicado hasta la fecha si el virus es excretado en la secreción vaginal, y con ello, el riesgo estimado de transmisión en parto vaginal. En relación a los otros brotes mencionados anteriormente, la vía de parto no tenía influencia en el riesgo de transmisión vertical.

\section{RECOMENDACIONES}

Dado el reciente e incompleto conocimiento que existe en relación a COVID-19, las recomendaciones se basan en esta información parcial, y en el aprendizaje obtenido de brotes anteriores de los otros coronavirus, y de la reciente epidemia de influenza $A$ H1N1 y su impacto en la embarazada.

Estas recomendaciones pueden ir cambiando en el tiempo según la evolución del brote en nuestro país, y de la nueva información generada en relación al virus y embarazo.

Distintos grupos de trabajo han hacho recomendaciones interinas. Acá recogemos lo más importante de varias de ellas (CDC, SOGC, ACOG) (10-12).

-Dado que comenzará el otoño y se aproxima la temporada de influenza, es prioritario incentivar la 
vacunación contra esta infección en todas las embarazadas y en el personal de salud.

Ya se sabe que puede existir confección de Influenza con SARS-CoV-2.

Mientras mayor sea el número de embarazadas inmunizadas, se reducirá el número de consultas por cuadro respiratorio que requiera hacer el diagnóstico diferencial y poner en marcha toda la logística que se requerirá frente a casos sospechosos.

Además, se reducirá el número de pacientes coinfectadas, que pudiesen tener teóricamente mayor gravedad del cuadro.

-Los equipos de salud que atiendan personas con síntomas respiratorios, deben estar muy atentos a consultar por antecedentes de viaje a países donde ya está ocurriendo transmisión comunitaria del virus, o si ha tenido contacto con personas con COVID-19 o con alguien con neumonía de etiología no aclarada

-La embarazadas debiesen evitar viajar a ciudades donde hay transmisión comunitaria de SARS-CoV-2, salvo que el viaje tenga razones impostergables.

-Las maternidades deben organizar en forma anticipada lo que será el manejo de embarazadas con COVID-19 o sospechosas de ello, tanto en el servicio de urgencia obstétrico, como en la zona de prepartos / partos, zona de recuperación así como en las zonas de alto riesgo obstétrico hospitalizado y en Puerperio. Esta toma de decisiones debe ser consensuada entre los equipos de medicina interna/infectología, obstetricia, neonatología y otros que sean necesarios.

-Las recomendaciones generales deberán ser adaptadas a las realidades locales de cada maternidad, cantidad de personal, espacios físicos, etc.

-Se debe contar con Unidades Aisladas para la atención en todo el proceso desde la consulta al servicio de urgencia maternal hasta el alta del hospital.

-Se debe actualizar la información y capacitación de todo el personal que podrá atender a una embarazada sospechosa o confirmada, y supervisar una adecuada adherencia a estas normas.
-Se debe contar con el adecuado equipo material en todas las etapas del proceso de atención.

-Se debe tener la organización adecuada para proteger al recién nacido de la transmisión del virus.

-Si una embarazada sospechosa o confirmada, va en camino a la maternidad transportada por una ambulancia, ésta debe prevenir antes de la llegada al hospital de la situación para que el equipo que la atenderá coloque a andar sus protocolos.

-Una embarazada con COVID-19 o sospechosa de ello, debe ser instalada en una sala con medidas de aislamiento correspondiente. $\mathrm{Si}$ el servicio de urgencia donde está consultando no cuenta con ello, deberá ser trasladada lo más rápido posible a una maternidad que sí lo tenga.

-Para reducir el riesgo de transmisión del virus de la madre al recién nacido, se podría considerar la separación temporal de la madre confirmada o bajo sospecha, hasta que las medidas de prevención en ella hayan sido suspendidas.

-Los recién nacidos hijos de madres confirmadas con COVID-19 o sospechosas debiesen ser considerados "personas bajo vigilancia" (PUI, de la sigla en inglés), y ser protegidos para evitar su contagio. Para ello se puede aislar a la madre hasta que las precauciones de transmisión viral de ella sean levantadas. Aún hay insuficientes datos para saber si el compromiso infeccioso en recién nacidos tiene o no una evolución severa.

-Los riesgos y beneficios de la separación temporal deben ser discutidos con la madre.

-Si se opta por la separación temporal, se debe restringir las visitas a ese niño que está en vigilancia, salvo un familiar asintomático y que pueda colaborar en su cuidado. El acompañante también debe tomar todas las medidas de precaución correspondientes, incluida pechera, guantes, mascarilla y protección ocular, lo mismo que el personal que atiene al recién nacido.

-La suspensión de la separación debe ser considerada caso a caso, según evolución clínica 
(síntomas, severidad) y de los resultados de exámenes de laboratorio.

-Si no se optó por la separación temporal, la madre confirmada o sospechosa debe realizar higiene de manos y usar mascarilla cada vez que va a atender o amamantar a su recién nacido. Dentro de la habitación se debe considerar la máxima separación que sea posible entre la cuna y la cama de la mamá.

-Las recomendaciones en relación a la forma de comenzar la lactancia debiesen ser analizadas en conjunto con la madre

-La preocupación principal, de acuerdo a la evidencia actual, no es si el virus puede ser transmitido por la leche materna, sino más bien el riesgo de que la madre pueda transmitirle el virus durante el contacto con su hijo para atenderlo o amamantarlo. Por eso, la frenación de la lactancia no forma parte primaria de estas recomendaciones, dada la importancia de la leche materna en la prevención de muchas otras enfermedades para el recién nacido.

En los estudios realizados anteriormente con otro coronavirus, SARS-CoV, y con el actual SARS-CoV-2 no se ha detectado virus en la leche. Sin embargo, aún es una variable que debe seguir investigándose dado la aún muy reciente aparición de este nuevo virus.

En el caso de otro virus respiratorio del cual se posee más información, como es el virus Influenza, el CDC ha recomendado que la madre infectada continúe amamantando o extrayendo su leche para alimentar a su recién nacido, bajo las precauciones correspondientes.

-Una madre con COVID-19 confirmado o sintomática sospechosa debe tomar todas las precauciones para evitar la diseminación a su hijo, incluyendo el lavado de manos antes de tocar a su RN y usar mascarilla durante el amamantamiento. Si lo va a amamantar con extracción de leche, debe lavar sus manos antes de manipular el extractor y seguir las indicaciones estrictas de aseo del extractor posterior a su utilización. Se debiese destinar un extractor exclusivo para esa madre.
-Si es posible, considerar a un miembro del equipo de salud o familiar capacitado y asintomático para amamantar al RN con la leche extraída.

\section{Revisión que sustenta la presente Editorial fue realizada 08 de marzo 2020.}

\section{REFERENCIAS}

1. Coronavirus. www.WHO.int/es/healthtopics/coronavirus

2. Coronavirus Disease (COVID-19) https://www.paho.org/hq/index.php?option=com content\&view=article\&id=15720:technicaldocuments-coronavirus-disease-covid19\&ltemid=4206\&lang=es

3. Yudin MH, Steele DM, Sgro MD, et al. Severe acute respiratory syndrome in pregnancy. Obstet Gynecol 2005; 105:124e7.

4. Wong SF, Chow KM, Leung TN, Ng WF, Ng TK, Shek CC, Ng PC, Lam PW, Ho LC, To WW, Lai ST, Yan WW Pregnancy and perinatal outcomes of women with severe acute respiratory syndrome. Am J Obstet Gynecol. 2004 Jul; 191(1):292-7.

5. Lauren J. Stockman, Sara A. Lowther, Karen Coy, Jenny Saw, and Umesh D. Parashar. . SARS during Pregnancy, United States. Letters. Emerging Infectious Diseases. 2004; 10(9)

6. Wong SF, Chow KM, de Swiet M. Severe acute respiratory syndrome and pregnancy. BJOG 2003;110:641 e2.

7. Coronavirus Disease (COVID-19) https://www.paho.org/en/topics/coronavirusinfections/coronavirus-disease-covid-19

8. Chen H, Guo J, Wang C, Luo F, Yu X, Zhang W, et al. Clinical characteristics and intrauterine vertical transmission potential of COVID-19 infection in nine pregnant women: a retrospective review of medical records. Lancet 2020; DOI: 10.1016/S0140-6736(20)30360-3.

http://www.sciencedirect.com/science/article/pii/ S0140673620303603. Retrieved Feb 21, 2020.

9. Niu $\mathrm{Y}$, Yue $\mathrm{H}$. Wuhan Tongji Hospital diagnoses first case of neonatal infection with new coronavirus.

http://society.people.com.cn/n1/2020/0205/c100 8-31572959.html 
10. Novel Coronavirus 2019. American College of Obstetricians and Gynecologists (ACOG). https://www.acog.org/en/Topics/COVID-19

11. Pregnancy \& Breastfeeding .Information about Coronavirus Disease 2019. Center for Disease Control and Prevention (CDC), https://www.cdc.gov/coronavirus/2019ncov/prepare/pregnancy-

Breastfeeding.html?CDC_AA_refVal=https $\% 3 \mathrm{~A}$ \%2F\%2Fwww.cdc.gov\%2Fcoronavirus\%2F2019 -ncov\%2Fspecific-groups\%2Fpregnancyfaq.html

12. Coronavirus infection and pregnancy. Royal College of Obstetrics \& Gynaecologists (RCOG).

13. https://www.rcog.org.uk/en/guidelines-researchservices/guidelines/coronaviruspregnancy/covid-19-virus-infection-andpregnancy/

14. Abarzúa C F, De Jourdan F, Rabagliati R, Cabib C. hospitalización por influenza en el servicio de obstetricia del hospital clínico de la Pontificia Universidad Católica, durante el primer año de recomendación de vacuna anti-influenza para embarazadas en Chile. Rev Chil Obstet Ginecol $2005 ; 70(4): 247-252$.

Dr. Fernando Abarzúa Camus Especialista en Medicina Materno Fetal Hospital Regional de Temuco

Clínica Alemana Temuco

Director Soc. Austral Obst. Gine. SOCHOG

Director Rama MMF SOCHOG 